\section{Mammary Abscess}

“M.B. " writes: In reply to "Suburban G.P." (March 14th, p. 480), the probable causation of these cases is as follows. Mothers of all classes seem firmly to believe that they must moisten the nipple with saliva before putting it in the baby's mouth. The probable sequence of events is dental sepsis, unwashed nipples, cracked nipples, mammary abscess. Few mothers take the trouble to wash and dry the nipple after nursing; a mere wipe is not enough. Very often the left breast is used more than the right; it is usually the first one given when both are used at a feed, and it is often given alone. I do not consider spirit or any hardening agent necessary for the nipples, but careful cleansing most certainly is essential.

\section{Paroxysmal Rhinorrhoea}

Dr. J. Fulton Christie (Glasgow) writes in reply to "Ninety-nine" (March 7th, p. 432): The history is that of a typical case of paroxysmal rhinorrhoea or vasomotor rhinitis. Recently I have been treating a series of patients suffering from this condition with parathyroid extract $1 / 10$ grain and calcium lactate 15 grains twice daily, over a period of six weeks. This treatment has been described before, and is not original. The results which I have been getting have been good, a definite improvement being obtained in almost every case. It is essential that septic tonsils or sinus disease, when present, should be first dealt with. The doses stated are for an adult.

\section{A Headache Poxider}

"W. F." was called to see an adult male patient who was in great distress. Five hours earlier he had taken a "head and nerve powder" for a headache and gone to lie down in bed. An hour later he began to feel queer, and when his wife saw him she became alarmed at his appearance. Our correspondent saw the patient five hours atter taking the powder. His eyes were then puffed and almost closed, and his face was greatly swollen. He said his head felt as if it were going to burst, and be was weak all over. The pulse rate was 96 . The symptoms soon subsided.

** The sample powder forwarded by " IV. F." has been examined on our behalf, and was found to contain acetanilide and tartaric acid, approximately 8 grains of the former and 2 grains of the latter in the 10-grain powder. The Pharmacopoeial dose of acetanilide is 2 to 5 grains.

\section{Miscarriage of One Twin}

We have received the following from Dr. H. CoHex (Cardiff): Dr. Boyd Roberts's note in the Journal of March 14th (p. 479) recalls to my mind that just over two years ago $I$ attended a primipara in her confinement, which was a fairly easy forceps case, followed by a perfectly normal third stage. The puerperium was uneventful, till on the fifth day she passed what strongly resembled a carneous mole. This was preceded by some uterine pain, but little or no haemorrhage. The temperature and general condition remained undisturbed, and the patient's progress was uninterrupted. $\Lambda$ s the expelled tissue was certainly not placenta or recent blood clot, I could only explain what happened by supposing that she had had a twin conception, and that one foetus had " missed fire", resulting in a blood mole, which was retained and not cast off till after labour took place. I may add that six months ago the patient had a second baby, both the confinement and puerperium being normal.

\section{LETTERS, NOTES, ETC.}

\section{Diverticula of the Duodenum.}

Dr. Jules Rfy (Bognor) writes: I add two more cases to the list for those who are interested in this condition. (1) A woman, aged 42, who was labelled a "neurotic" and " hysterical" derelict, drifted into my hands and, among other investigations and tests, I gave her a barium meal. The startling discovery was made that she had a diverticulum about 3 to $4 \mathrm{~cm}$. in diameter, almost globular, and situated in the third part of the duodenum or first part of the jejunum. Unfortunately, owing to the exigencies of my practice, I could not spare the time to photograph the condition. It could easily be emptied by deep massage in the middle line of the body. She fully recovered her former good health, due almost entirely to the frequent evacuation of the contents of this diverticulum by manual pressure. Five years have elapsed, and still, with careful dieting, she remains in very good health. (2) A married man came to me on March 11 th, complaining of dull con- stant epigastric pain. Appendicectomy had been done in December, 1930, with no relief. By $x$-ray examination a hypertonic stomach was found there being also increased peristalsis, an irregular duodenal cap, and duodenal ileus. Nine hours after ingestion, when the stomach was nearly empty, except for a faint crescent of the greater curvature, a very small diverticulum was seen at the junction of the first and second part of the duodenum, a respiratory excursion of 5 to $8 \mathrm{~cm}$. taking place. Several hours later the diverticulum had completely disappeared. It will be interesting to note if all his symptoms disappear with careful dieting and the administration of alkalis.

\section{Treatment of Obesity in a Multipara}

M.B., B.S." writes: Perhaps my personal experience may be of some help. After the birth of my second child I began to put on weight rapidly. From my normal weight of 11 st. $7 \mathrm{lb}$. I went up to nearly 14 st. I began to take Burroughs Wellcome's thyroid extract (fresh gland), beginning with doses of half a grain three times a day. pushed this gradually until I noticed signs of hyperthyroidism. This occurred when I was taking 20 grains a day. I reduced the dose to 15 grains a day, and I have gradually lost weight, and am now back to $11 \frac{1}{2}$ st. People remark on my slimness and youthful look. I am 38 years of age and $5 \mathrm{ft} .9 \mathrm{in}$. in height. I am now taking 15 grains every other day with my early morning tea. The slimming process I have described took eighteen months. The only drawback to this dosage that I have noticed is a feeling of tiredness towards the evening. I have had the same result in a patient who got suddenly fat after a confinement; but she needed only five grains a day to reduce her to normal.

\section{Treatment of Cancer of the Bladider}

Dr. W. M. Corbet (London, E.C.) writes: The article just published under the above heading will further trouble the muddy waters for the average practitioner. To the urologist the position is crystal clear, and reduces itself to the indication for immediate cystoscopy at the onset of any urinary haemorrhage. A cancer of the bladder is never fulminating $a b$ initio, like, for example, a melanotic sarcoma. Practical experience in cystoscopy teaches one that these growths almost always commence as benign papillomata, responding readily to trans-urethral diathermy with a sufficiently powerful current and a sufficiently heavy electrode. They only gradually take on malignant characteristics; and the vesical neoplasm which, when seen for the first time, whether by abdominal section or cystoscopically, is undoubtedly malignant, is a growth seen too late-as much so as if it were situated in the breast or the lip. The obtaining of a proper specimen for microscopical examination is usually not practical proposition. The writer, while stressing the difficulty of exact diagnosis of the stage of malignancy, lays down excision as the method of choice. I think most urologists would agree with me in placing excision third on the list and advising, first, cystoscopic diathermy-under sacra anaesthesia if need be-and, secondly, open diathermy. Radium, in my experience, is a lamentable failure in this region, only prolonging the agony. The quoted statistical mortality of 75 per cent. in vesical cancer is surely the strongest plea for the early cystoscopic exploration I urge.

\section{Analgesia in Childbirth}

Dr. A. Z. C. CRessy (Wallington) writes: In a letter published in the British Medical Journal of October 25th, 1930, referred to ovarian residue in labour, and I have since had letters on the subject from doctors in China, America, Africa, Ireland, Scotland, and several in England, all asking for details. This shows that the general practitioner is on the look out for anything that may improve his practice, and that he does take an interest in midwifery.

\section{Corrigendum}

We regret that in Mr. Holt Diggle's paper entitled "Intranasal dacryocystostomy for relief of lacrymal obstruction," published in our issue of March 7th (p. 391), the word "apart" was erroneously inserted in the following sentence: "Other factors ... no doubt prejudiced a favourable result in what was apart from the consistency of the sac an easy operation."

\section{Vacancies}

Notifications of offices vacant in universities, medical colleges, and of vacant resident and other appointments at hospitals, will be found at pages $53,54,55,56,57,60$, and 61 of our advertisement columns, and advertisements as to partnerships, assistantships, and locumtenencies at pages 58 and 59 .

A short summary of vacant posts notified in the advertisement columns appears in the Supplement at page 95. \title{
$\frac{2}{\frac{2}{2}}$
}

